\title{
SOBRE VULNERABILIDADE ESCOLAR DE ESTUDANTES TRANS
}

\author{
FERNANDO GUIMARÃES OLIVEIRA DA SILVA ${ }^{1}$
}

\author{
ELIANE ROSE MAIO ${ }^{2}$
}

\begin{abstract}
Resumo: Este texto é resultado de diálogos que pulsam na busca por movimentos de desconstrução das verdades sobre a identidade de gênero de meninas trans. Assinalamos 'verdades', porque nos filiamos à ideia de que não há uma única maneira de se apresentar como menina trans para o mundo social, como muitos/as acreditam na transgenitalização. Nossa incursão prevê problematizar como a escola pode produzir diferentes vulnerabilidades quando há uma transitoriedade identitária que (des)identifica o gênero culturalmente sexuado e permite com que meninas trans convivam com diferentes maneiras de expressar suas feminilidades. Buscamos, no recorte da pesquisa bibliográfica, tendo como recurso a revisão sistemática de literatura, leituras diversas que asseguram seu espaço de reflexão nos estudos culturais, para analisar como a Escola tem se colocado frente ao conjunto de im/possibilidades de se experimentar processos de (des)identificações e (des)generificadores de corpos sexuados.

Palavras-chave: Trans. Vulnerabilidades. (Des)identificações.
\end{abstract}

Abstract: This text is the result of dialogues that pulsate in the seek for movements of deconstruction of the truths about the gender identity of trans girls. We point out 'truths' because we are affiliated to the idea that there is not a one way to present as a trans girl to the social world, as many believe in transgendering. Our incursion foresees how school can produce different vulnerabilities when there is a transience of identity that (un)identifies the culturally sexed gender and allows trans girls to coexist with different ways of expressing their feminities. In the cut of bibliographical research, having as a resource the systematic review of literature, we seek diverse readings that assure their space of reflection in the cultural studies, in order to analyze how school has been placed in front of the set of im/possibilities of experiencing processes of (des)identifications and (de)generators of sexed bodies.

Key words: Trans. Vulnerabilities. (Des)identifications.

Resumen: Este texto es el resultado de diálogos que pulsan en la búsqueda por movimientos de desconstrucción de las verdades sobre la identidad de género de niñas trans. Señalamos 'verdades', porque nos filiamos a la idea de que no hay una manera única de presentarse como niña trans al mundo social, como muchos creen en la transgenitalización. Nuestra incursión prevé problematizar cómo la escuela puede producir diferentes vulnerabilidades cuando hay una transitoriedad identitaria que (des)identifica el género culturalmente sexuado y permite que las niñas trans convivan con diferentes maneras de expresar sus feminidades. Se buscan lecturas diversas en el recorte de la investigación bibliográfica, teniendo como recurso la revisión sistemática de literatura, que aseguran su espacio de reflexión en los estudios culturales, para analizar cómo la Escuela se ha colocado frente al conjunto de im/posibilidades de experimentar procesos de (des)identificaciones y (des)generadores de cuerpos sexuados.

\footnotetext{
${ }^{1}$ Doutorando em Educação pela Universidade Estadual de Maringá (UEM). Professor Universitário em Três Lagoas/MS e Coordenador do CRAS junto à Prefeitura Municipal de Ilha Solteira/SP. É integrante do Núcleo de Estudos e Pesquisas em Diversidade Sexual (NUDISEX).

${ }^{2}$ Pós Doutora e Doutora em Educação pela Universidade Estadual Paulista (UNESP/Araraquara). Professora do Programa de Pós Graduação (Mestrado/Doutorado) em Educação da Universidade Estadual de Maringá (UEM). Coordena o Núcleo de Estudos e Pesquisas em Diversidade Sexual (NUDISEX).
}

Rev. Diversidade e Educação, v. 5, n. 1, p. 24-31, jan./jun. 2017. 
Palabras clave: Trans. Vulnerabilidades. (Des)identificaciones.

\section{Introdução}

Neste texto propomos enunciar sobre pessoas que convivem cotidianamente marcadas por discursos de ódio, práticas de violência, e que vivenciam casos de desacesso, especialmente nas escolas. Pretendemos tornar este texto parte integrante de um conjunto de problematizações sobre o universo trans e que auxiliarão profissionais da educação a se questionarem sobre o que estão oportunizando aos/às suas/seus estudantes transgêneros. Queremos produzir o deslocamento do centro às margens, considerando que o centro é vastamente usado por aqueles/as pessoas que estão na instância do normativo e, com isso, não experimentam nenhuma ação violenta, ou não, advinda da transfobia, considerada como as margens do normativo.

O objetivo central é tornar possível a multiplicidade de maneiras de se apresentar trans e estar na escola, promover acessos pedagógicos e formativos que auxiliem a comunidade escolar a reconhecer a diferença com fundamento na identidade de gêneros. Para tal, utilizamos dos estudos culturais para conciliar um universo incansável e significativo de verdades, que garantiram enunciar de espaços diversos, e que nos permite deslocar nossos conceitos tradicionais e conservadores para compreender o impossível enquanto um espaço de transformação, transnomeação, transitoriedade.

É certo que você, leitor/a, terá, de início, que acionar o seu conjunto de significados para visualizar o assunto, mas nós o/a convidamos para deixar de lado suas defesas e passar a compreender a do/da outro/a. Quem sabe não teremos condições de dialogar sem que possamos cair no desrespeito e em práticas de transfobia? Fomos enfáticos/as nesta indagação, porque cremos que, a priori, são acionados conceitos que indicam a impossibilidade de se pensar no/na outro/a e no que ele/ela faz de sua vida. Entretanto, para que nosso diálogo seja significativo para ambas as partes, precisamos de sua compreensão. Bom, vamos lá!

$\mathrm{Na}$ exposição que segue, apresentaremos um conjunto decididamente teórico e cientifico, que demonstrará a possibilidade de se experimentar o novo e o criativo como potência e vazão às regras e normas sociais que creem que somos determinados e marcados para seguir caminhos estreitamente rígidos referentes às experimentações sobre sexo, gênero e sexualidades. Já antecipamos que o pensamento sobre diversidades sexuais vai além do que devemos ser, ele traz consigo uma série de situações sociais e culturais que são convergidas na construção do modo como eu pretendo me identificar para o mundo e para as outras pessoas. Rev. Diversidade e Educação, v. 5, n. 1, p. 24-31, jan./jun. 2017. 
Envolve como me relaciono com estas construções culturais, se caminho no respeito a elas ou se resolvo subvertê-las.

Observamos que o cerne da discussão volta-se constantemente para a heterossexualidade como modelo hegemônico de experimentação do sexo, do gênero e da sexualidade. Porém, como aceitar isso com tanta certeza, se nas salas de aulas temos estudantes que se orientam com identidades de gêneros opostas ao que foi culturalmente instituída para o seu sexo ao nascer? A resposta disso nos desloca a assumir um compromisso social enquanto profissionais da educação, porque, se eu não aceito, não tem como fazer um acolhimento efetivo e tornar suas identidades parte do processo de ensino e aprendizagem. As nossas discussões em sala de aula nos convidam a filiarmos a explicações diversas sobre o assunto para não acontecer o que muitas pesquisas de doutorado e mestrado têm mostrado sobre o contato que estudantes trans têm com vulnerabilidades, uma vez que as escolas têm sido um ambiente hostil.

\section{Movimentos de (des)identificações trans: vulnerabilidades}

É válido destacar que entendemos por trans as estudantes travestis e transexuais, como bem aponta o Professor Wilian Peres (2009, p. 236): “identificam com a imagem e o estilo feminino, apropriando-se de indumentárias e adereços de sua estética, realizando com frequência a transformação de seus corpos, quer por meio da ingestão de hormônios, quer através da aplicação de silicone industrial e das cirurgias de correção estética e de próteses".

É difícil pensar trans quando não se flexibilizam os diferentes modos de se apresentar as feminilidades flutuantes no contexto social. Costumamos (re)produzir sob diferentes discursos que a detentora de feminilidade é apenas a mulher cisgênero, mas cometemos um erro sério. É possível compreender que mulheres trans também são produtoras de feminilidades, assim como outras demarcações de mulheres nos conduz a diferentes modos de produção da feminilidade.

Entendemos a feminilidade a partir da pluralidade de manifestações presentes em diferentes modos de ser e estar mulher em sociedade. Para fundamentar esta leitura, acreditamos que há uma feminilidade peculiar em mulheres negras, que podem ser adicionadas a outras questões sociais, econômicas e culturais que nos oportuniza crer num conjunto infinito de se expressar o feminino. Em relação às mulheres trans (travestis e transexuais), também é possível encontrar uma feminilidade peculiar. Hall (2000, p. 17) nos auxilia a visualizar a estrutura da identidade como uma celebração móvel. Celebrar a mobilidade de uma identidade significa Rev. Diversidade e Educação, v. 5, n. 1, p. 24-31, jan./jun. 2017. 
compreender que não há como instituir uma única maneira de se experimentar a identidade feminina e masculina, mas, devido a sua provisoriedade, abertura constante e perturbadora a pessoa se vê frente a diferentes maneiras de expressar o masculino e o feminino.

Compreender que podemos experimentar diferentes maneiras de ser masculino e feminino se apresenta como um desafio para a academia, principalmente em pesquisas em educação. Nos estudos de Rogério Dinis Junqueira (2009, p. 33), as “diversas pesquisas têm revelado que as travestis constituem a parcela com maiores dificuldades de permanência na escola de inserção no mercado de trabalho em função do preconceito e da discriminação sistemática". O quadro das pesquisas, segundo o autor, evidencia os conflitos existentes no processo de reconhecimento das travestilidades, determinando "a supressão completa e arbitrária de direitos e de oportunidades, seja por razões jurídico-formais, seja pelo puro e simples exercício da força física bruta ou em virtude dos efeitos simbólicos das representações sociais" (RIOS, 2009, p. 63).

O conceito de vulnerabilidade que utilizamos encontra seu significado no dicionário ao ser definido como um "estado de fragilidade das pessoas que as tornam suscetíveis a riscos" (HOUAISS, 2009, s/p). Nesse caso, queremos entender como as pesquisas denunciam os riscos que estão expostas as trans nas escolas. O quadro das pesquisas demonstra que as transfobias ocorridas nas escolas se apóiam no "não-reconhecimento, configurando uma espécie de ostracismo social, nega valor a um modo de ser ou de viver, criando condições para formas de tratamento degradantes e insultuosas" (RIOS, 2009, p. 72). Nessa mesma direção, Peres (2009, p. 245) comentou que a marginalização das trans na escola decorre da "intensidade da discriminação e do desrespeito aos quais as travestis são expostas nas escolas em que desejam estudar leva, na maioria das vezes, a reações de agressividade e revolta, ocasionando o abandono dos estudos ou a expulsão da escola". Relacionado a isso, outro dado relevante emerge na segregação que se alarga em ações que explicitam a ausência de enfrentamento ao estigma e preconceito direcionado a esse público (JUNQUEIRA, 2009).

É fato que as trans têm demarcado em si a "subversão da identidade única e possível" (SILVA, 2000). Chamamos de identidade única e possível as práticas que direcionam como os corpos devem culturalmente satisfazer a demarcações socioculturais para os sexos, ou melhor como os sexos devem agir em relação ao gênero. Demarcadas pelo desrespeito da fronteira socialmente imposta para os gêneros, o estigma que acompanha a identidade de meninas trans refrata os discursos preconceituosos apensos aos ditos sobre a subversão que fazem da identidade heterossexual. Assim, discursos, como: travestis são prostitutas, usuárias de drogas, Rev. Diversidade e Educação, v. 5, n. 1, p. 24-31, jan./jun. 2017. 
desrespeitam regras e normas, usam maquiagens fortes, parecem mulheres artificiais, dentre outras imagens que se consolidam, ressoam com uma representação negativa delas, "porque fica patente a supremacia heterossexista no convívio social" (RIOS, 2009, p. 77).

Diante dos efeitos simbólicos da reprodução do discurso heterossexualizante, as estudantes transgêneros estão propícias a experimentarem diferentes riscos e vulnerabilidades nas escolas. Elas perturbam a ordem do discurso sobre a orientação sexual considerada modelopadrão. Na relação que estabelecem com a comunidade escolar, perdas significativas enredam suas cidadanias e fortalecem nelas, o pensamento de que não fazem parte daquele contexto, porque não se submeteu às determinações e cobranças sociais para os corpos sexuados. Berenice Bento (2011) considera corpos sexuados o movimento interno feito pela cultura para naturalização de alguns objetos sociais como sendo pertencentes à vagina e ao pênis, inscrevendo regras no usufruto do gênero. Em suas palavras: "Aquilo que evocamos como um dado natural, o corpo-sexuado, é resultado das normas de gênero" (BENTO, 2011, p. 554).

É relevante dar destaque à Berenice Bento (2011), uma vez que suas pesquisas trazem de maneira significativa o movimento de (des)identificação que tende a tirar de uma regra para colocação em outra regra. Queremos tirar um corpo de um processo de identificação, mas o colocamos em outro. Tiramos corpos trans do mundo binário, mas ainda tentamos estabilizálos em uma única maneira de identificação: o gênero masculino ou feminino. Acreditamos que, por ser trans, geralmente há uma negação do órgão genital, porém, Bento (2011) nos traz que há um conjunto infinito de representação do gênero e necessariamente não é o órgão genital que oferece esta sensação de ser masculino ou feminino. Muitas não vêem problema na transição do corpo para identidade de gênero feminina e continuam com o pênis, outras já preferem fazer cirurgias de transgenitalização. Ao pesquisar diferentes expressividades trans, ela nos convida a pensar a potência criativa das delas que as colocam fora dos estereótipos que estamos acostumados a enquadrá-las.

É por conta de diferentes possibilidades de ser e estar trans, que oferecer tratamentos sociais com fundamento no pênis ou na vagina, para assegurar, respectivamente, masculinidades e feminilidades, não assegura o respeito à identidade de gênero das/dos estudantes. Para Junqueira (2009), o processo de constituição identitária como trans é doloroso e vulnerável em função do estranhamento que as imagens dela conduzem em comparação com modelos sociais de gênero; produz

Rev. Diversidade e Educação, v. 5, n. 1, p. 24-31, jan./jun. 2017. 
desinteresse pela escola; produz distorção idade-série, abandono e evasão; prejudica a inserção no mercado de trabalho; enseja uma visibilidade distorcida; vulnerabiliza física e psicologicamente; tumultua o processo de configuração e expressão identitária; afeta a construção da autoestima; influencia a vida socioafetiva (JUNQUEIRA, 2009, p. 24).

Abarcar o conceito de vulnerabilidade pelo viés pessoal nos auxilia a entender como os recursos simbólicos, por sua vez normativos, presentes nas escolas, atuam na construção do sentimento de pertença e envolvimento com as atividades da escola. Acolher ou (des)acolher? Problematizamos este assunto porque a escolarização é um direito e, se segrega, gera quadros de exclusão e contato com situações de riscos e vulnerabilidades àqueles que se sentem como distantes dos padrões socialmente aceitos neste espaço.

Marina Reidel (2013, p. 65) afirma que: "Se a escola tradicional não as ensinou, elas aprenderam o resto na escola da vida". Expõe uma denúncia à impossibilidade de conclusão do ensino fundamental e médio por estudantes trans porque as escolas as excluem, mesmo antes da entrada. Assinala diferentes práticas responsáveis por expulsá-las: "fatores como pressão, o estigma, o nome ou até mesmo o não saber lidar com essa pessoa, faz com que a fuga da escola possa acontecer" (REIDEL, 2013, p. 64).

Frente à iminência da vulnerabilidade, o que podemos fazer para prevenir estas situações? Não queremos trazer receitas, até porque quem detém o poder de fabricar a sua identidade docente e pedagógica é o/a professor/a. Ele/a, segundo Martin Lawn (2001, p. 123) será responsável por acreditar que sua prática poderá transformar percursos formativos, o que nos leva a compreender que a sua "identidade é construída, quer contra, quer a favor de algo". Inferimos, então, que se você, enquanto professor/a, profissional da Educação, que tem um compromisso social, vai para a escola instituir suas crenças, o espaço da escola torna-se individualizante.

Nós, professores/as, temos que construir possibilidades de fazer nossos/as estudantes sentirem-se pertencidos/das àquilo que os/as orientam. Não podemos colocar uma verdade única sobre aquilo que fazemos. Em sala de aula, estamos na condição de adultos de referência, se fabricamos nossa identidade em contraposição às manifestações religiosas, gêneros, socioeconômicas e etc. de nossos/nossas estudantes, o compromisso do/da Professor/a já não é mais político e sim, intolerante.

Berenice Bento (2011, p. 552), novamente, afirma que as práticas sociais e escolares encontram fundamento nas reiterações das normas de gêneros e no heteroterrorismo. Enfatiza

Rev. Diversidade e Educação, v. 5, n. 1, p. 24-31, jan./jun. 2017. 
que há um processo normatizador em que diversas instituições sociais reiteram a produção do gênero, utilizando de um vasto arsenal discursivo que marcam na heterossexualidade um terrorismo contínuo. De acordo com a autora, as escolas têm poder de hierarquizar corpos sexuados, porque a produção de seres abjetos e a desumanização das pessoas trans, gays e lésbicas são uma garantia de reprodução da heteronormatividade.

Pode a escola ser um ambiente de convivência com infinitas possibilidades de se reinventar? Acreditamos que a indagação não é esta, mas sim: sabendo da criatividade dos/das estudantes de se inventarem são possíveis a criação de práticas escolares que diminuam vulnerabilidades nos processos formativos de estudantes trans? Vimos que esta possibilidade ressoa positiva quando se compreende que o espaço da escola é público e de todos/as, o que torna esta discussão emergente devido às cenas de transfobias que têm se ampliado na sociedade.

Nossa prática tem uma dinâmica formativa bastante séria para ser utilizada como recurso de contraposição a diversidade sexual. Ela não deve ser utilizada para ser espaço de piadas que oferecem descrédito às identidades transgêneros. Principalmente, porque enquanto parte de uma relação social, ela produz subjetividades. Se as subjetividades forem produzidas de maneira subversiva e longe das normas heterossexuais, o processo de auto reconhecimento destas estudantes será permeado de contextos transfóbicos.

\section{Considerações Finais}

Esperamos ter oportunizado discussões que as/os levassem a compreender a potência de nossa prática educativa para produzir vulnerabilidade ou para converter quadros de vulnerabilidades em proteção, acolhimento e apoio às identidades transgêneros que estão pela escola. Sabemos que foi difícil se desvencilhar de suas crenças para entender melhor como estas diferenças estão acontecendo na escola, mas esperamos ter conduzido sua reflexão para entender que identidades transgêneros convivem com um universo simbólico limitado e determinante de riscos e atos que as tornam vulneráveis. Nossa problematização caminha para tê-lo/la como mais um adulto de referência que crie condições de acolhimento para estudantes trans e, sobretudo, contribua para a diminuição de quadros de desistência, abandono e evasão escolares. Cremos que é conferido a você, profissional da educação, significativa atribuição nesse processo, pois você é responsável por dar autonomia e vazão para pensar o impossível enquanto categoria de transformação de pessoas e subversão de normas sociais.

Rev. Diversidade e Educação, v. 5, n. 1, p. 24-31, jan./jun. 2017. 


\section{Referências:}

BENTO, B. Na escola se aprende que a diferença faz a diferença. Estudos Feministas, Florianópolis, 19(2): 548-559, maio-agosto/2011.

HOUAISS. Dicionário eletrônico Houaiss da língua portuguesa. Rio de Janeiro: Objetiva, 2009.

JUNQUEIRA, R. D. Homofobia nas escolas: um problema de todos. In: JUNQUEIRA, R. D. Diversidade sexual na educação: problematização sobre a homofobia nas escolas. Brasília: MEC/SECAD, 2009.

LAWN, M. Os professores e a fabricação de identidades. Currículo sem Fronteiras, v.1, n.2, pp. 117-130, Jul/Dez 2001

PERES, W. S. Cenas de exclusão anunciadas: travestis, transexuais, transgêneros e a escola brasileira. In: JUNQUEIRA, R. D. Diversidade sexual na educação: problematização sobre a homofobia nas escolas. Brasília: MEC/SECAD, 2009. p. 235-264.

REIDEL, M. Ser trans e as interlocuções com a educação. In: NARDI, H. C; SILVEIRA, R. da S; MACHADO, P. S. Diversidade sexual, relações de gênero e políticas públicas. Porto Alegre: Sulina, 2013. p. 62-72.

RIOS, R. R. Homofobia na perspectiva dos direitos humanos e nos contextos dos estudos sobre preconceito e discriminação. In: JUNQUEIRA, R. D. Diversidade sexual na educação: problematização sobre a homofobia nas escolas. Brasília: MEC/SECAD, 2009. p. 53-84.

SILVA, T. T. (Org). Identidade e diferença: a perspectiva dos estudos culturais. Tomaz Tadeu Silva (org.), Petrópolis, RJ: Vozes, 2000.

Recebido em: 31/05/17

Aceito em: 10/07/17

Rev. Diversidade e Educação, v. 5, n. 1, p. 24-31, jan./jun. 2017. 